\title{
New records of avian nasal mites (Mesostigmata: Rhinonyssidae) to Southeastern Brazil
}

\author{
Julia C. Takatsu' ${ }^{1 \oplus}$, Ricardo Bassini-Silva ${ }^{1,2(\infty)}$, Greg S. Spicer ${ }^{3 \oplus}$, Erika Hingst-Zaher ${ }^{4 \oplus}$, Fernando \\ de C. Jacinavicius ${ }^{1 \pm=0}$
}

${ }^{1}$ Laboratório de Coleções Zoológicas, Instituto Butantan, São Paulo, SP, Brazil. ${ }^{2}$ Departamento de Patologia, Reprodução e Saúde Única, Faculdade de Ciências Agrárias e Veterinárias-UNESP, Jaboticabal, SP, Brazil. ${ }^{3}$ Department of Biology, San Francisco State University, San Francisco, CA, USA. ${ }^{4}$ Museu Biológico, Instituto Butantan, São Paulo, SP, Brazil.

拝"'Corresponding author: fcjacinavicius@gmail.com

Edited by: Jose W. S. Melo (Guest Editor)

Received: October 30, 2021. Accepted: November 10, 2021. Published: December 07, 2021.

\begin{abstract}
The avian nasal mites are a group of Mesostigmata, belonging to the family Rhinonyssidae, Trouessart, 1895, obligate endoparasites of the respiratory system of birds. In Brazil, seven of the eight genera of this family have been recorded. After examining the Acarological Collection of the Instituto Butantan, the species Rallinyssus gallinulae Fain, 1960 and Rhinoecius bisetosus Strandtmann, 1952 were identified from Gallinula galeata (Lichtenstein, 1818) (Gruiformes: Rallidae) and an unidentified owl, respectively. In this study, we are recording for the first time $R$. gallinulae from Brazil (Rio de Janeiro State), while R. bisetosus is recorded for the second time to this country (São Paulo State), however from a different specific locality.
\end{abstract}

Keywords: Avian nasal mites, endoparasites, Rio de Janeiro State, São Paulo State, Rallidae, Strigidae.

The family Rhinonyssidae Trouessart, 1895, popular known as avian nasal mites, is a group of Mesostigmata mites, obligate endoparasites of the respiratory system of birds. Currently, this family comprises about 600 species into eight genera - Larinyssus Strandtmann, 1948; Ptilonyssus Berlese \& Trouessart, 1889; Rallinyssus Strandtmann, 1948; Rhinoecius Cooreman, 1946; Rhinonyssus Trouessart, 1894; Ruandanyssus Fain, 1957; Sternostoma Berlese \& Trouessart, 1889; Tinaminyssus Strandtmann \& Wharton, 1958 (Pence 1975). Of these genera, seven have already been recorded in Brazil, except for Ruandanyssus, unique to the Asia and Oceania region (Pence 1975; Mascarenhas et al. 2018).

The genus Rallinyssus encompasses twelve species, $R a$. amaurornis Wilson, 1965; Ra. caudistigmus Strandtmann, 1948; Ra. congolensis Fain, 1956; Ra. cychramus Wilson, 1965; Ra. gallinulae Fain, 1960; Ra. limnocoracis Fain, 1956; Ra. porzanae Wilson, 1967; Ra. rallinae Wilson, 1966; Ra. sorae Pence \& Young, 1979; Ra. strandtmanni Gretillat, 1961; Ra. trappi Amaral, 1962; and Ra. verheyeni Fain, 1963, which are exclusive parasites of rails (Gruiformes: Rallidae). There are only two species recorded to South America. One of these species - $R$. trappi - was described from Brazil, collected on the Blackish Rail, Pardirallus nigricans (Vieillot, 1819) (cited as Ortygonax nigricans) (Gruiformes: Rallidae) in Itaporanga Municipality, São Paulo State (Amaral 1962a). While, Ra. caudistigmus was collected in Neuquen province, Argentina, parasitizing the Red-gartered Coot, Fulica armillata Vieillot, 1817 (Gruiformes: Rallidae) (Kun \& Vega 2016).

The genus Rhinoecius also has twelve species, all of which are exclusive parasites of owls: Rh. aegolii Butenko, 1971; Rh. africanus Zumpt \& Patterson, 1951; Rh. alifanovi Butenko, 1976; Rh. bisetosus Strandtmann, 1952; Rh. brikinboricus Butenko, 1976; Rh. cavannus Wilson, 1968; Rh. cooremani Strandtmann, 1952; Rh. grandis Strandtmann, 1952; Rh. nycteae Butenko, 1976; Rh. oti Cooreman, 1946; Rh. subbisetosus Bregetova, 1965; and Rh. tytonis Fain, 1956. So far, two species have been recorded in Brazil: Rh. bisetosus and $R h$. grandis, both originally described from Texas, USA (Strandtmann 1952), and later recorded in Brazil by Amaral (1962b). Rhinoecius bisetosus has been reported parasitizing the Burrowing Owl, Athene cunicularia grallaria (Temminck, 1822) (cited as Speotyto cunicularia grallaria) (Strigiformes: Strigidae) in Itaporanga Municipality, São Paulo State and $R$. grandis has been reported parasitizing the Band-bellied owl, Pulsatrix melanota (Tschudi, 1844) (Strigiformes: Strigidae) in Boracéia Municipality, São Paulo State (Amaral 1962b). The present study provides new locality and host-association records for two species of avian nasal mites, as well as microscopy images that help in the identification of these species.

The examined material was slide-mounted and deposited in the Acarological Collection of the Instituto Butantan (IBSP) as "nonidentified specimen" and belongs to a collection dated from the 1930s. We tried to retrieve, as much information as possible, from the collection records, and from the original labels for each slide. The identification of genus and species was carried out according to the dichotomous keys made by Domrow (1969) and Pence (1975), and compared with the original descriptions of the species belonging to each genus.

The specimens were identified as Rallinyssus gallinulae (IBSP 254) and Rhinoecius bisetosus (IBSP 272, IBSP 273, and IBSP 274). A general view of the second species is shown in Fig. 1A. Rallinyssus gallinulae can be morphologically separated from the other Rallinyssus species due to the different shape of the opisthosomal and sternal shields (Figs. 1C and D). This species was originally described from the common moorhen, Gallinula chloropus (L., 1758) (Gruiformes: Rallidae) from Zoo d'Anvers, Belgium (Fain 1960). Our new record from the IBSP collection was collected in 1933, from the Common Gallinule, Gallinula galeata (Lichtenstein, 1818) (Gruiformes: Rallidae) in the Rio de Janeiro Municipality, Rio de Janeiro State. Although until 2014 the common moorhen and the common gallinule were considered the same species (del Hoyo et al. 2014), the first is restricted to the Old World, while G. galeata is restricted to the New World.

The other species, identified as $R h$. bisetosus was firstly described from Texas, USA, parasitizing the Burrowing Owl, Athene cunicularia (Temminck, 1822) (Strigiformes: Strigidae) (Strandtmann 1952), and 
recorded on this same host in Itaporanga Municipality, São Paulo State, Brazil (Amaral 1962b). Rhinoecius bisetosus can be easily distinguished from the other species of the genus by the very elongated setae on the propodosoma (Fig. 1B). By examining the specimens deposited in the IBSP collection, we hereby record this mite species parasitizing three different owl specimens, collected in the Park of Instituto Butantan, in the city of São Paulo, São Paulo State, in 1932, 1933, and 1934. These records represent a second locality of occurrence for $R h$. bisetosus in Brazil, and in a new locality of the São Paulo State.

Even though the label in the specimens and the collection catalog identifies the host merely as an owl, and not to the species level, it is possible to assume that the species of owl is the same for which $R$. bisetosus has been recorded in Texas and São Paulo. Since the turn of the $20^{\text {th }}$ century and until 1944, what is now the park of Instituto Butantan was part of a large farm, where the horses used in the production of antivenom serum were kept. Most of the area of the "Fazenda Butantã" became in 1941 the campus of the University of São Paulo (Prado 2005). Based on images from 1900 to 1940 it is possible to see that a large part of the area of this farm was comprised of grasslands and pasture, and even before that it was part of the so called "campos do Butantan" or fields of Butantan (Joly 1950). In that kind of habitat, the most abundant species of owl would have been the burrowing owl, Athena cunicularia. Therefore, it is reasonable to assume that this is the host species of the new records reported here.
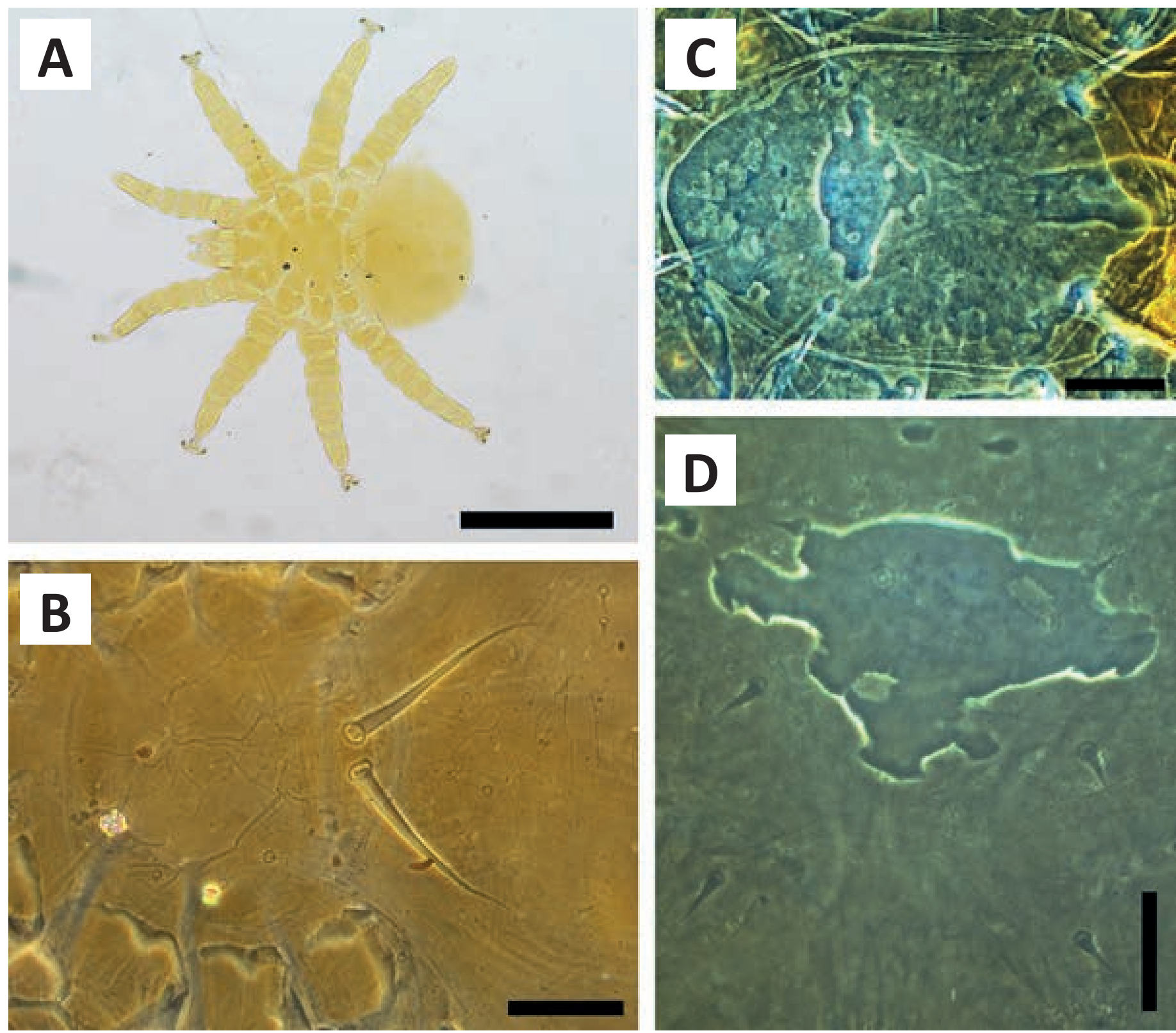

Figure 1. Microscopy images of Avian nasal mites (Rhinonyssidae). A. General view of Rhinoecius bisetosus Strandtmann, 1952; B. Details of the dorsal region of Rh. bisetosus; C. Propodosomal shield of Rallinyssus gallinulae Fain, 1960; D. Sternal shield Ra. gallinulae; Scale bars: A $500 \mu$, B, and C $100 \mu$, D $50 \mu$.

\section{Acknowledgements}

To Gabrielle Ribeiro de Andrade and Maria Cristina Ferreira do Rosário for technical contribution. This work was supported by the Fundação de Amparo à Pesquisa do Estado de São Paulo under the Grant FAPESP no. 2021/02295-4 (JCT), 2017/01416-7, 2018/246678 and 2020/11755-6 (RB-S), and 2019/19853-0 (FCJ). This study was financed in part by the Coordenação de Aperfeiçoamento de Pessoal de Nível Superior - Brasil (CAPES) - Finance Code 001.

\section{Authors' Contributions}

JCT and FCJ examined and remounted slides of avian nasal mites deposited in the IBSP Collection. FCJ and RB-S performed the study and confirmed the identification of the mites. EH-Z confirmed the identification of the hosts. JCT, RB-S, EH-Z, and FCJ wrote the manuscript. 


\section{References}

Amaral, V. (1962a) Rallinyssoides trappi n. sp. (Acarina: Rhinonyssidae Vitz.1935) parasita da saracura-sana (Ortygonyx nigricans (Vieillot). Arquivos do Instituto Biológico, 29: 185-191.

Amaral, V. (1962b) Sternostoma augei n. sp. (Acarina: Rhinonyssidae Vitz.,1935) e identificação das espécies Rhinoecius bisetosus Strandtmann, 1952 e Rhinoecius grandis Strandtmann, 1952. Arquivos do Instituto Biológico, 29: 69-81.

Beron, P. (2020) Acarorum Catalogus VI. Order Mesostigmata. Gamasina: Dermanyssoidea (Rhinonyssidae, Spinturnicidae). Sofia: Pensoft. doi: 10.3897/ab.e54206

del Hoyo, J.; Collar, N. J.; Christie, D. A.; Elliott, A.; Fishpool, L. D. C. (2014) HBW and BirdLife International Illustrated Checklist of the Birds of the World. Volume 1: Non-passerines. Spain: Barcelona and UK: Cambridge: Lynx Edicions BirdLife International.

Dimov, I. (2020) Taxonomic diversity and morphology of mites of the family Rhinonyssidae of the northwest of Russia. Saint Petersburg: Krin.

Domrow, R. (1969) The nasal mites of Queensland birds (Acrai: Dermanyssidae, Ereynetidae, and Epidermoptidae). Proceedings of the Linnean Society of New South Wales, 93: 297-426.

Fain, A. (1960) Rallinyssus gallinulae n.sp. et Rallinyssoides n.g. parasites de Rallidae avec une clé des Rhinonyssidae (Acarina: Mesostigmata). Bulletin et Annales de la Societe Royale Belge d'Entomologie, 96(11-12): 293-302.

Joly, A. B. (1950) Estudo Fitogeográfico dos Campos de Butantan (São Paulo). Boletim Da Faculdade de Filosofia, Ciências e Letras, Universidade de São Paulo. Botânica, 8: 5-68.

Kun, M. E.; Vega, R. M. (2016) First record of the nasal mite Rallinyssus caudistigmus Strandtmann (Acari: Rhinonyssidae) from Argentina. Revista de la Sociedad Entomológica Argentina, 75 (1-2): 97-100.

Mascarenhas, C. S.; Bernadon, F. F.; Gastal, S.; Muller, G. (2018) Checklist of the parasitic nasal mites of birds in Brazil. Systematic \& Applied Acarology, 23(8): 1672-1692. doi: 10.11158/saa.23.8.15

Pence, D. B. (1975) Keys, species and host list, and bibliography for nasal mites of North American birds (Acarina: Rhinonyssinae, Turbinoptinae, Speleognathinae, and Cytiditidae). Special Publications. Museum of Texas Tech University, 8: 1-148.

Prado, M. L. C. (2005) Cidades universitárias: patrimônio urbanístico e arquitetônico da USP. Centro de Preservação Cultural. São Paulo: Editora da Universidade de São Paulo.

Strandtmann, R. W. (1952) The mesostigmatic nasal mites of birds, III. New species of Rhinoecius from owls. Proceedings of the Entomological Society of Washington, 54: 205-216. 